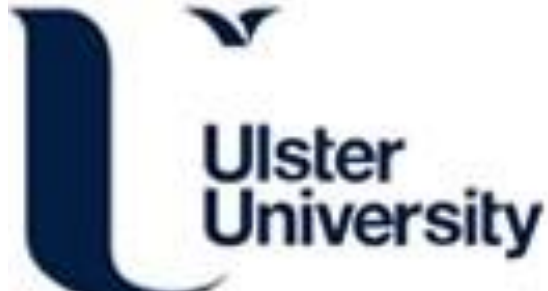

On the role of alternatives in the acquisition of simple and complex disjunctions in French and Japanese

Tieu, L., Yatsushiro, A., Cremers, A., Romoli, J., Sauerland, U., \& Chemla, E. (2017). On the role of alternatives in the acquisition of simple and complex disjunctions in French and Japanese. Journal of Semantics, 34(1), 127152. https://doi.org/10.1093/jos/ffw010

Link to publication record in Ulster University Research Portal

\section{Published in:}

Journal of Semantics

Publication Status:

Published (in print/issue): 01/02/2017

DOI:

10.1093/jos/ffw010

\section{Document Version}

Author Accepted version

\section{General rights}

Copyright for the publications made accessible via Ulster University's Research Portal is retained by the author(s) and / or other copyright owners and it is a condition of accessing these publications that users recognise and abide by the legal requirements associated with these rights.

\section{Take down policy}

The Research Portal is Ulster University's institutional repository that provides access to Ulster's research outputs. Every effort has been made to ensure that content in the Research Portal does not infringe any person's rights, or applicable UK laws. If you discover content in the Research Portal that you believe breaches copyright or violates any law, please contact pure-support@ulster.ac.uk. 


\title{
On the role of alternatives in the acquisition of simple and complex disjunctions in French and Japanese*
}

\author{
L. Tieu ${ }^{1}$, K. Yatsushiro ${ }^{2}$, A. Cremers ${ }^{1}$, J. Romoli ${ }^{3}$, U. Sauerland ${ }^{2}$, and E. Chemla ${ }^{1}$ \\ ${ }^{1}$ Laboratoire de Sciences Cognitives et Psycholinguistique, Ecole Normale Supérieure, Paris \\ ${ }^{2}$ Zentrum für Allgemeine Sprachwissenschaft (ZAS), Berlin \\ ${ }^{3}$ University of Ulster
}

June 12, 2016

\begin{abstract}
When interpreting disjunctive sentences of the form 'A or B,' young children have been reported to differ from adults in two ways. First, children have been reported to interpret disjunction inclusively rather than exclusively, accepting 'A or B' in contexts in which both A and B are true (Gualmini, Crain, Meroni, Chierchia \& Guasti 2001: Chierchia, Crain, Guasti \& Thornton 2001). Second, some children have been reported to interpret disjunction conjunctively, rejecting 'A or B' in contexts in which only one of the disjuncts is true (Paris 1973; Braine \& Rumain 1981; Chierchia, Guasti, Gualmini, Meroni, Crain \& Foppolo 2004; Singh, Wexler, Astle, Kamawar \& Fox 2015). In this paper, we extend the investigation of children's interpretation of disjunction to include both simple and complex forms of disjunction, in two typologically unrelated languages: French and Japanese. First, given that complex disjunctions have been argued to give rise to obligatory exclusivity inferences (Spector 2014), we investigated whether the obligatoriness of the inference would play a role in the acquisition of the exclusive interpretation. Second, using a paradigm that makes the use of disjunction felicitous, we aimed to establish whether the finding of conjunctive interpretations would be replicated for both simple and complex forms of disjunction, and in languages other than English. The main findings from our experiment are that both French- and Japanese-speaking children interpreted the simple and complex disjunctions either inclusively or conjunctively; in contrast, adults generally accessed exclusive readings of
\end{abstract}

${ }^{*}$ For helpful feedback and discussion, we would like to thank the audiences at the 25th Semantics and Linguistic Theory conference, the Ecole Normale Supérieure, Université Paris Diderot, and ZAS, as well as three anonymous reviewers and the editors at Journal of Semantics. We are also grateful to Yoichi Miyamoto for collecting data in Japan, Anne-Caroline Fievet for coordinating testing at local preschools in Paris, and Shala Nourmamode for recording the French stimuli. We would also like to acknowledge the families, directors, and teachers at the Paris and Osaka preschools who participated in our studies. The research leading to this work was supported by the European Research Council under the European Union's Seventh Framework Programme (FP/2007-2013) / ERC Grant Agreement n.313610, ANR-10-IDEX-0001-02 PSL*, ANR-10-LABX-0087 IEC, and DFG-Grant SA 925/11-1 within XPrag.de (SPP 1727) and BMBF grant 01UG1411. 
both disjunctions. We argue that our results lend further support to the proposal put forth in Singh et al. (2015), according to which the reason some children compute conjunctive meanings while adults compute exclusive meanings is that the two groups differ in their respective sets of alternatives for disjunction. Crucially, adults access conjunction as an alternative to disjunction, and compute exclusive interpretations; in contrast, children access only the individual disjuncts as alternatives, and therefore either interpret the disjunction literally or compute conjunctive inferences. More generally, our findings can be explained quite naturally within recent proposals according to which children differ from adults in the computation of scalar inferences because they are more restricted than adults in the set of scalar alternatives they can access (Barner, Brooks \& Bale 2011; Tieu, Romoli, Zhou \& Crain 2015b, among others).

\section{Introduction}

Languages like French and Japanese have both simple and complex forms of disjunction. The simple forms of disjunction ou (1) and $k a(2)$ are typically interpreted exclusively by adults, i.e. schematically as $(\mathrm{A} \vee \mathrm{B}) \wedge \neg(\mathrm{A} \wedge \mathrm{B})$.

La poule a poussé le bus ou l'avion
DET-hen push-PAST DET-bus OU DET-airplane

'The hen pushed the bus or the airplane.'

Niwatori-san-wa Bus-ka hikooki-o osita

hen-SAN-TOP Bus-KA airplane-ACC push-PAST

'The hen pushed the bus or the airplane.'
French

Japanese

The literal inclusive meaning of disjunction (3a) can be strengthened to an exclusive "notboth' interpretation (3c) by means of comparing the disjunctive sentence with the stronger conjunctive alternative in (3b). Assuming the speaker is as informative as she can be (Grice 1975), the fact that she uttered the disjunction rather than the stronger conjunction can lead us to conclude that the stronger alternative must be false (3c) (for more recent conceptualizations, see van Rooij \& Schulz 2004; Sauerland, Andersen \& Yatsushiro 2005; and Spector 2007).

The hen pushed the bus or the airplane.

a. The hen pushed the bus or the airplane or both.

b. The hen pushed the bus and the airplane.

c. The hen pushed the bus or the airplane but not both.

We can also capture the strengthened meaning by means of a grammaticalized exhaustification operator EXH, as schematized in (4). This exhaustification operator takes a proposition and its alternatives, and affirms the proposition while negating any alternatives that (i) are not entailed by the assertion, and (ii) the negation of which doesn't entail another alternative (Spector 2007; Fox 2007; see also Spector (to appear) for a comparison of different versions of $\mathrm{ExH}){ }^{1}$

\footnotetext{
${ }^{1}$ Note that while we make use of the ExH-based approach for the purposes of the exposition, the acquisition
} 
$\operatorname{EXH}($ The hen pushed the bus or the airplane $)=$

The hen pushed the bus or the airplane and nOT(The hen pushed the bus and the airplane)

Note that the exclusivity inference in (3c) is cancellable, as shown by the acceptable continuation in (5).

(5) The hen pushed the bus or the airplane. In fact, she pushed both.

In contrast to the simple forms in (1) and (2), the complex forms of disjunction in (6) and (7), where French ou and Japanese $k a$ are replaced by soit...soit and $k a . . . k a$, respectively, are reported to give rise to exclusive readings obligatorily (Spector 2014) ? $^{2}$

La poule a poussé soit le bus soit l'avion

DET-hen push-PAST SOIT DET-bus SOIT DET-airplane

'The hen pushed either the bus or the airplane.'

Niwatori-san-wa Bus-ka hikooki-ka-o osita

hen-SAN-TOP Bus-KA airplane-KA-ACC push-PAST

'The hen pushed either the bus or the airplane.'

Spector (2014) reports that unlike the exclusivity inference associated with the simple disjunction ou, the exclusivity inference associated with soit...soit cannot be cancelled, as shown by the contrast between (8) and $(9)]^{3}$
a. Marie ira au cinéma lundi ou mardi.
'Mary will go to the movies on Monday or Tuesday'
b. Absolument ! Et elle ira même à la fois lundi ET mardi.
'Absolutely! She will even go both days.'
a. Marie ira au cinéma soit lundi soit mardi.
'Mary will go to the movies SOIT on Monday soit on Tuesday'
b. \#Absolument ! Et elle ira même à la fois lundi ET mardi.
'Absolutely! She will even go on both days.'

Given the difference in the obligatoriness of the exclusivity inference, Spector $(2014)$ proposes that soit...soit occurs obligatorily under the scope of an exhaustivity operator.

In this paper, we set out to investigate children's comprehension of both simple and complex forms of disjunction, in both French and Japanese. In particular, we examined the role of obligatoriness in the acquisition of the exclusivity inference, by investigating whether

study we will describe does not hinge on a particular account of implicature, nor does it set out to adjudicate between competing accounts of implicature.

${ }^{2}$ As indicated in the translations in (6) and (7) a similar equivalent in English may be either...or, which also seems to be interpreted more exclusively than the simple disjunction or.

${ }^{3}$ Like other scalar implicatures, the exclusivity inference associated with simple disjunction typically disappears in downward-entailing environments such as the scope of negation. It is less simple to assess the presence of the implicature in the case of the complex disjunction, as soit...soit is a positive polarity item (PPI); in the antecedent of a conditional, however, soit...soit receives an inclusive interpretation. See Spector (2014) Section 5.1 for discussion of the licensing of PPI soit...soit in restrictors. 
children distinguish simple and complex disjunctions in terms of the readings they assign.

In the next section, we will review previous findings about the acquisition of disjunction. Then we will present our experiment, conducted with French- and Japanese-speaking children, and discuss our findings in light of recent proposals concerning children's ability to compute scalar implicatures.

\section{Acquisition of disjunction}

There are two main findings from previous work on the acquisition of disjunction that will be relevant to our discussion. The first is that children typically accept a disjunctive description 'A or B' in contexts in which both $\mathrm{A}$ and $\mathrm{B}$ are true. The second is that children have been reported to reject 'A or $\mathrm{B}$ ' when only one of the two disjuncts is true.

\subsection{Children are inclusive rather than exclusive}

Children have been reported to interpret disjunction more 'literally' than adults, accepting disjunctive descriptions of situations in which both disjuncts are made true (Paris 1973; Braine \& Rumain 1981; Chierchia, Crain, Guasti \& Thornton 2001; Gualmini, Crain, Meroni, Chierchia \& Guasti 2001). For example, in a situation where the character Bunny paints both a car and a truck, adults, but not children, tend to reject the description Bunny painted the car or the truck. The usual interpretation of such a finding is that while adults are able to compute an implicature of exclusivity from the disjunction, e.g., Bunny painted the car or the truck, but not both, children access an inclusive interpretation of the disjunction, e.g., Bunny painted the car or the truck, or both.

This finding that children compute fewer exclusivity inferences than adults is consistent with much previous work on the acquisition of scalar implicatures. In much of this literature, it has been shown that children tend to be more accepting than adults are of underinformative sentences (Noveck 2001; Papafragou \& Musolino 2003; Barner, Brooks \& Bale 2011, among many others). For example, in a situation where three out of three horses jump over a fence, children, unlike adults, tend to accept the description Some of the horses jumped over the fence. As in the previous case of disjunction, the usual interpretation here is that children, unlike adults, fail to compute the scalar implicature Some but not all of the horses jumped over the fence.

Previous findings on children's abilities to access exclusive meanings of disjunction have focused on simple disjunction in English. In our study, we raise the question of whether children might access more exclusive readings of complex forms of disjunction. In particular, given that the exclusivity inference has been argued to be obligatory for complex disjunctions, we investigate whether children acquiring languages that have both simple and complex forms of disjunction are more likely to interpret the complex form exclusively than the simple form.

\subsection{Children interpret disjunction conjunctively}

Another previous finding concerning children's interpretation of disjunction has been that some children interpret the disjunction conjunctively, rejecting disjunctive descriptions of 
situations in which only one disjunct is true (Paris 1973; Braine \& Rumain 1981; Chierchia, Guasti, Gualmini, Meroni, Crain \& Foppolo 2004; Singh, Wexler, Astle, Kamawar \& Fox 2015). One possible explanation of such a finding is that these children are simply confusing the lexical items for disjunction and conjunction, e.g., or and and in English. As Singh et al. (2015) point out, however, various studies in the developmental literature indicate that there is no such conjunctive behaviour in downward-entailing environments. Children acquiring English, Mandarin Chinese, and Japanese, for example, have been shown to assign an adult-like inclusive semantics for disjunction in the scope of negation (Crain, Gardner, Gualmini \& Rabbin 2002; Gualmini \& Crain 2002; Goro \& Akiba 2004; Jing, Crain \& Hsu 2005). That is, they interpret the disjunction inclusively, adhering to De Morgan's laws, as in (10a), and do not appear to interpret the disjunction as conjunction, as in (10b).

The pig didn't eat the carrot or the pepper.

a. $\quad \rightsquigarrow$ The pig didn't eat the carrot and the pig didn't eat the pepper

b. $\quad \Varangle \rightarrow$ It's not the case that the pig ate both the carrot and the pepper

Further evidence against a lexical misanalysis account of children's conjunctive behaviour on disjunction can be found in their inclusive interpretation of disjunction in various other downward-entailing environments: the scope of before in English and zai...zhiqian 'before' in Mandarin (Notley, Zhou, Jensen \& Crain 2012), the restrictor of every (Gualmini, Meroni \& Crain 2003; Su 2013), the nuclear scope of not every (Notley, Zhou, Jensen \& Crain 2012), only (Goro, Minai \& Crain 2005; Jing, Crain \& Hsu 2005), none (Gualmini \& Crain 2002), and nobody (Su, Zhou \& Crain 2012), and in the antecedent of the conditional ruguo in Mandarin (Su 2014). $\mathrm{Su}(2014)$ provides further evidence that children as a group distinguish disjunction and conjunction in the consequent of conditionals. In a context in which both disjuncts/conjuncts in the consequent are made true, Su reports that children accept (11) less than $15 \%$ of the time, compared to over $90 \%$ of the time in response to (12).

If the swordfish walks out of the maze, then he will get a butterfly or a crown. If the swordfish walks out of the maze, then he will get a butterfly and a crown.

Taken together, the findings of these studies argue quite strongly against the idea that children assign a conjunctive lexical semantics to the disjunction, and render the finding of a conjunctive interpretation in unembedded contexts a rather surprising one. One natural concern is whether the conjunctive interpretation was simply an artefact of the particular task that Singh et al. (2015) used. In particular, they used a Truth Value Judgment Task (Crain \& Thornton 1998), but with static pictures rather than full stories, and presented the test sentences in Description mode rather than Prediction mode. That is, the puppet would utter the disjunctive test sentence after having already seen the picture. For example, participants would be shown either a picture of a boy holding a banana and an apple, or a picture in which the apple was on a table and the boy was holding only the banana. A puppet, who could see the picture as well, would then describe the picture using a disjunctive test sentence, e.g., The boy is holding an apple or a banana.

There are two worries one may have about such materials. First, static images may not provide enough of a context to constrain possible interpretations and make the relevant 
readings plausible, especially for young children. Second, the use of disjunction typically gives rise to an ignorance inference that the speaker does not know which of the two disjunct holds. If uttered in Description mode then, the puppet's assertion is rather infelicitous, given he can see which of the disjuncts holds in the picture 4 One of the goals of the experiment to be presented in Section 3 then, is to determine whether the finding of conjunctive interpretations is replicable, once these methodological concerns are addressed.

To account for their results in light of the previous literature suggesting that children have an inclusive semantics for disjunction in downward-entailing environments, Singh et al. (2015) propose an account that explains both why children tend to be more inclusive than adults, and why some children appear to interpret disjunction conjunctively. Their proposal appeals to current explanations of children's difficulties with scalar implicatures. Before we look at their account, it may be instructive to consider briefly this background upon which Singh et al. build their proposal.

\subsubsection{On the role of alternatives in children's implicatures}

According to recent proposals in the developmental literature on implicatures, children are capable of computing scalar implicatures when the scalar alternatives that they require are made easily accessible (Chierchia, Crain, Guasti \& Thornton 2001; Gualmini, Crain, Meroni, Chierchia \& Guasti 2001; Barner, Brooks \& Bale 2011; Tieu, Romoli, Zhou \& Crain 2015b). On these proposals, children may indeed fail to compute the implicature in (13b) from (13a), but this is not due to a general inability to compute implicatures; rather children have difficulty retrieving all as a lexical scalar alternative to some.5

a. Some of the horses jumped over the fence.

b. $\operatorname{NOT}($ All of the horses jumped over the fence)

Such a hypothesis concerning children's performance on scalar implicatures finds evidence from a few sources. For example, when children are presented with the two scalar alternatives explicitly, they are capable of selecting the stronger alternative. Chierchia et al. (2001) and Gualmini et al. (2001) show, for example, that in a context in which both disjuncts are true, children are more likely to reward a puppet who utters the stronger alternative in (14b) than a puppet who utters the weaker alternative in (14a).

a. Every dwarf chose a bike or a skateboard.

b. Every dwarf chose a bike and a skateboard.

Children's performance on scalar implicatures has also been shown to be improved by the insertion of an overt only, though crucially only in cases where the alternatives are context-

\footnotetext{
${ }^{4}$ These methodological concerns are particularly worrisome given Singh et al. report that they had to exclude 25 of the 56 children they tested, after these children failed to perform significantly above chance on controls.

${ }^{5}$ As Tieu et al. (2015b) point out, the precise difficulty children encounter with alternatives may have to do with lexical retrieval, e.g., a difficulty retrieving all from the lexicon when presented with some, or it may have to do with lexical development, i.e. children must lexicalize some and all as co-scalar alternatives. Either way, if it is not made explicit to the child that all is indeed an alternative to some, children are expected to fail to compute the implicature.
} 
dependent, i.e. explicitly provided in the context (Barner et al. 2011). For example, when shown a picture of a cat, a cow, and a dog, all of which are sleeping, children correctly reject (15a), unlike (15b). No facilitatory effect is found when the quantifier some is used, however; even with the presence of only in (16a), children fail to reject the sentence. The interpretation of this result is that children are capable of carrying out the procedure by which strengthened meanings are derived, e.g., exhaustification, but only when they can access the lexical alternatives that are required for the relevant inference.

a. Only the cat and the dog are sleeping.

b. The cat and the dog are sleeping.

a. Only some of the animals are sleeping.

b. Some of the animals are sleeping.

Finally, the hypothesis that children can compute implicatures not involving lexical retrieval of alternatives is elaborated upon by Tieu et al. (2015b), who show that children are capable of computing free choice inferences. A sentence containing the modal is allowed to and disjunction, such as (17a), for example, gives rise to the free choice inference in (17b), according to which Jack has free choice between the two options.

a. Jack is allowed to have ice cream or cake.

b. $\rightsquigarrow$ Jack is allowed to have ice cream and Jack is allowed to have cake.

This case is telling, because free choice inferences have been argued to be derived as a kind of scalar implicature (Kratzer \& Shimoyama 2002; Alonso Ovalle 2005; Fox 2007; Klinedinst 2007; Chemla 2009; van Rooij 2010; Franke 2011; Chierchia 2013). Crucially, the alternatives that are required to compute the free choice inference are present as substrings of the assertion. According to Fox (2007), for example, we recursively exhaustify (18a) as in (18b), negating the alternatives in (18c) and (18d) in order to generate the free choice inference in (18e).

a. Jack is allowed to have ice cream or cake.

b. $\operatorname{EXH}(\operatorname{EXH}(J a c k$ is allowed to have ice cream or cake $))$

c. $\operatorname{EXH}(J a c k$ is allowed to have ice cream), i.e. Jack is only allowed to have ice cream

d. $\operatorname{EXH}($ Jack is allowed to have cake), i.e. Jack is only allowed to have cake

e. $\rightsquigarrow \operatorname{NOT}(\operatorname{EXH}(J a c k$ is allowed to have ice cream) ) and $\operatorname{NOT}(\operatorname{EXH}(\mathrm{Jack}$ is allowed to have cake))

i.e. Jack is allowed to have ice cream and Jack is allowed to have cake

Crucially, the alternatives that we need to negate correspond to the (pre-exhaustified) disjuncts of the original assertion, so children do not need to perform any lexical replacements or retrieve any alternatives from the lexicon. Zhou et al. (2013) and Tieu et al. (2015b) tested 4- and 5-year-old children's comprehension of free choice inferences, and found that children were successful at rejecting free choice statements in contexts where only one of the disjuncts was true, e.g., when Jack was only allowed to have ice cream. While they failed to compute classical scalar implicatures involving or/and and might/must, their performance 
on free choice inferences was adult-like.

Taken together, these studies suggest that children are capable of accessing strengthened meanings; where they encounter difficulty is accessing the scalar alternatives from which they can derive those strengthened meanings.

\subsubsection{Conjunction through recursive exhaustification}

Now let us return to the observation that some children appear to interpret disjunction conjunctively. Singh et al.'s (2015) proposal is that children arrive at this conjunctive interpretation through a non-adult-like implicature. Children recursively exhaustify the disjunctive statement 'A or B', effectively rendering it equivalent to the conjunctive statement 'A and B'. Working within the larger alternatives-based approach to children's performance on implicatures, Singh et al. argue that children are indeed capable of exhaustifying, i.e. of accessing strengthened meanings, just as adults are. Crucially however, children exhaustify over a different set of alternatives from adults: unlike that of adults, children's set of alternatives is not closed under conjunction. Let us demonstrate the disparity between children and adults through an example.

When presented with the sentence in (19), adults have the conjunction as an alternative (19a), and compute the exclusivity implicature in (19b). Children, on the other hand, exhaustify as in (20a). Rather than accessing conjunction as an alternative, they access the individual disjuncts in (20b) and (20c), generating the conjunctive implicature in (20d).

(19) The bunny painted the car or the truck.

a. The bunny painted the car and the truck.

b. $\quad$ NOT(The bunny painted the car and the truck)

i.e. The bunny didn't paint both the car and the truck

(20) The bunny painted the car or the truck.

a. $\operatorname{EXH}(\operatorname{EXH}($ The bunny painted the car or the truck $))$

b. $\operatorname{EXH}($ The bunny painted the car), i.e. The bunny only painted the car

c. $\operatorname{EXH}($ The bunny painted the truck), i.e. The bunny only painted the truck

d. NOT(EXH(The bunny painted the car)) and NOT(EXH(The bunny painted the truck))

i.e. The bunny painted both the car and the truck

As Singh et al. point out, the way that children arrive at the conjunctive reading of disjunction, according to their proposal, is exactly the same way that adults arrive at free choice inferences (as we saw in (18) $]^{6}$ As they note, their proposal therefore makes the prediction that children should be capable of computing free choice inferences, and this prediction is indeed borne out (Zhou et al. 2013; Tieu et al. 2015b).

In summary, Singh et al.'s (2015) account builds on previous findings that children only compute strengthened meanings off of the alternatives that they can access. Their explanation succeeds in accounting both for the observation that children often fail to compute

\footnotetext{
${ }^{6}$ See also Meyer $(2015)$ for a related proposal concerning adults' conjunctive interpretations of disjunction in certain linguistic contexts.
} 
exclusivity inferences, and for the observation that some children access a conjunctive interpretation of disjunction.

\subsubsection{Ignorance inferences}

Before we move on to our experiment, we will briefly mention here one further study that merits closer examination in light of Singh et al.'s findings of conjunctive interpretations of disjunction. Hochstein, Bale, Fox \& Barner (2014) compared 4- and 5-year-old Englishspeaking children's performance on ignorance implicatures such as (21b) and scalar implicatures such as $(22 \mathrm{~b})$.

a. The bear took a plate or a cup.

b. $\rightsquigarrow$ The speaker does not know whether or not the bear took a plate, and the speaker does not know whether or not the bear took a cup.

a. Each animal has an apple or a strawberry.

b. $\rightsquigarrow$ It is not the case that each animal has both an apple and a strawberry.

Hochstein et al. point out that on standard neo-Gricean accounts, the derivation of (21b) and $(22 \mathrm{~b})$ involve the same computations and formal alternatives, with the only difference being the strength of the final inference (see Hochstein et al. 2014:8-9 for details). To test whether 4- and 5-year-old children could compute ignorance inferences such as (21b), the authors presented children with a task in which they would hear a disjunctive statement, and then had to decide if that statement was uttered by an action figure who could see what had happened, or by a blindfolded action figure who could not see what was happening. The rationale was that if children computed the ignorance implicature associated with the disjunctive sentence, they would attribute it to the blindfolded character.

Hochstein et al. (2014) report that while the 5-year-olds they tested failed to compute the scalar implicature in (22b), most of them nevertheless sucessfully computed the ignorance implicatures, attributing the disjunctive statements to the blindfolded puppet. This was the case whether only one, or both of the disjuncts were made true. As an anonymous reviewer points out, if some children always computed conjunctive interpretations of the disjunction, then when both disjuncts were made true in Hochstein et al.'s experiment, these children should have selected the 'seeing' puppet rather than the blindfolded puppet. More generally, the conjunctive meaning for disjunction reported in Singh et al. (2015) should imply that the speaker believes both of the disjuncts are true. If some children compute conjunctive meanings for disjunction, they should not compute ignorance implicatures about each of the disjuncts. On the face of it, the two sets of findings are not immediately compatible.

While a systematic comparison of the two studies would take us too far afield for the present purposes, we remain optimistic that a better understanding of the precise conditions that drive children towards one reading of the disjunction over another will ultimately explain the potential disparity between the Singh et al. and Hochstein et al. findings. For example, since the two tasks targeted distinct inferences, they naturally differed in various ways, including the nature of the task and the question that was asked of the children. In order to better understand the compatibility of the two sets of findings, we need a better understanding of what factors push children to compute certain inferences in some cases but 
not others.

For our purposes, we will deliberately set aside the issue of ignorance by focusing on what interpretation children assign to the disjunction - when this disjunction is felicitously uttered. We will do so by implementing a guessing game (i.e. a Truth Value Judgment Task in Prediction mode), in which it will be made clear to participants from the outset that the speaker is ignorant as to the outcome; therefore the judgments should have nothing to do with whether or not the speaker was ignorant, only with whether the disjunctive statement described the outcome.

\subsection{Our study}

Previous results reveal that children typically interpret disjunction inclusively, and sometimes access a conjunctive interpretation of disjunction. Many of these studies have been restricted to simple disjunction in English, however. In our study, we raise three new research questions, which have not been addressed in any of the previous studies on children's comprehension of disjunctive sentences.

First, does the obligatoriness of the exclusivity inference for complex disjunction play a role in children's acquisition of exclusive readings? Free choice inferences have been argued to be obligatory, and as we have seen, 4-year-old children appear to perform better on these than classical scalar implicatures (Zhou et al. 2013; Tieu et al. 2015a). Another kind of implicature that sees improved performance in children is the exactly- $n$ interpretation of numerals (Papafragou \& Musolino 2003; Huang, Spelke \& Snedeker 2013). Huang et al. (2013) and Papafragou \& Musolino (2003) propose that children's relatively improved performance on numerals provides evidence for an exact semantics for numerals. While the analysis of numerals remains controversial, a potential alternative explanation is that the exactly$n$ meaning arises as an obligatory implicature, and (assuming obligatory implicatures are acquired earlier) is therefore acquired earlier than optional implicatures.

The idea that obligatoriness might play a role in the acquisition of a particular reading becomes quite natural on the basis of considerations of the kind of evidence the child learner may receive in her input. If the exclusivity inference is obligatory in the case of the complex disjunction, it stands to reason that whenever the child encounters this form of disjunction in her input, it will arise in a context that makes the exclusive reading of the disjunction true, i.e. that verifies only one of the disjuncts. On the other hand, the exclusive interpretation of the simple disjunction, while it may be preferred, is not obligatory. We may therefore expect to find evidence of the simple disjunction being used both in those contexts that support the inclusive reading and those that support the exclusive reading. In other words, the child should receive categorical evidence for the exclusivity of complex disjunction, but perhaps more equivocal evidence for simple disjunction. This difference provides a natural grounds for investigating the role of obligatoriness in the acquisition of the exclusive interpretation of the different forms of disjunction.

A second goal of the present study is to establish whether the conjunctive interpretation of disjunction can be replicated in languages other than English. The finding of conjunctive interpretations across different languages would speak further against the idea that children may simply confuse the morphemes for disjunction and conjunction. 
Finally, no previous studies have compared children's calculation of the exclusivity inference in both simple and complex forms of disjunction. While it might be plausible that children confuse the morphemes for conjunction and simple disjunction, it seems less likely that children would confuse the morphemes for conjunction and complex disjunction. Moreover, given that exclusive readings are argued to be obligatory for complex disjunctions, it would be surprising to see children accessing the non-adult-like conjunctive interpretation of the complex form. On the other hand, Singh et al.'s (2015) proposal would predict that conjunctive interpretations should be possible for both forms: if children lack the conjunctive alternative but can compute conjunctive inferences from the individual disjuncts, they may do so in the case of the complex disjunction, just as they do for simple disjunction.

\section{Experiment}

We designed an experiment to investigate the comprehension of simple and complex forms of disjunction in French and Japanese, i.e. ou/soit...soit in French and $k a / k a \ldots k a$ in Japanese. Our experiment was conducted in French and Japanese, but the materials will be described here in English. The original French and Japanese materials can be found in the Appendix.

\subsection{Method}

\subsubsection{Participants}

We tested 28 French-speaking children $(3 ; 07-6 ; 06, \mathrm{M}=4 ; 05)$ at local preschools in Paris, and 18 Japanese-speaking children $(4 ; 07-6 ; 06, \mathrm{M}=5 ; 05)$ at a preschool in Osaka. We also tested 20 adult native speakers of French at the Ecole Normale Supérieure in Paris, and 21 adult native speakers of Japanese at the University of Osaka, using the same materials and procedure 7 French adults were paid $3 €$ for their participation, while Japanese adults were paid $500 ¥$.

These sample sizes were chosen on the basis of practical considerations. We decided before any testing began that we would test as many French- and Japanese-speaking children as we could gain access to in the Paris and Osaka preschools. The final sample sizes are similar to those reported in previous Truth Value Judgment Task experiments in the developmental literature on scalar implicatures.

\subsubsection{Procedure}

We used a modified Truth Value Judgment Task (Crain \& Thornton 1998, 2000) in Prediction mode, presented to the participants in the form of a 'guessing game'. Participants were introduced to a puppet named Raffie the Giraffe, and were told that they would play a game with her on the computer. Pre-recorded videos of the puppet's utterances created the ruse that the puppet was participating live via webcam.

\footnotetext{
${ }^{7}$ These numbers exclude three Japanese and five French children who failed to pass the control trials. An additional two French children were excluded as it was reported that their first language was English. Finally, two Japanese adults were excluded for making at least two errors on control trials.
} 
The reason we chose to run the task in Prediction mode rather than the typical Description mode, where the puppet describes an event that has already unfolded, was meant to make the use of disjunction felicitous. In particular, the use of disjunction typically gives rise to an ignorance inference that the speaker does not know which of the two disjunct holds. If uttered in Description mode then, the puppet's assertion could have potentially given rise to infelicity, given the puppet had just witnessed the relevant event unfold.

Each trial consisted of three stages (see Figure 1). First, the participant would see a picture and hear a short introduction about the character in the picture. In the second step, the puppet would appear on the screen to make a guess about what would happen next in the story ${ }^{8}$ At this stage, children would also be prompted to repeat the puppet's sentence, to ensure that they had correctly heard the statement. In the final scene, participants saw the outcome, and had to decide if the puppet had guessed correctly or not. Participants had to stamp under a happy or sad face on a scorecard to indicate their responses. We also elicited follow-up justifications after affirmative and negative responses, in order to ascertain children's reasoning for their responses.

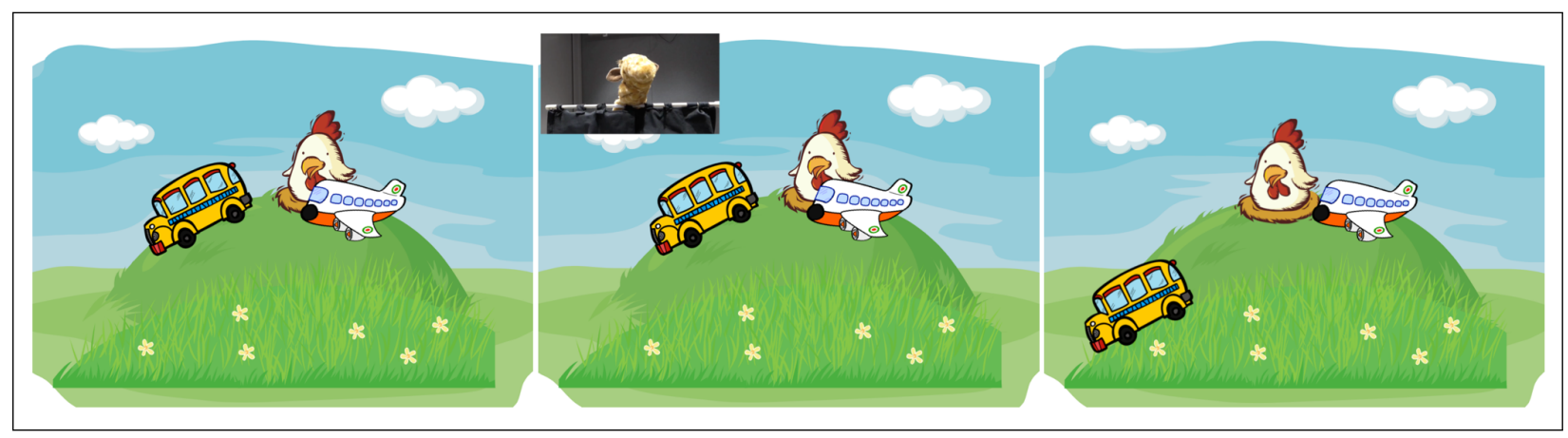

Figure 1: The three stages of an example trial, accompanying the test sentence The hen pushed (either) the bus or the airplane. Scene 1: There once was a hen who loved to play with her toys, and she especially loved to push them around! One day her papa gave her two new toys: a bus and an airplane! The hen was very happy to play with them. Let's see if Raffie can guess what happened next! Scene 2: ExPERIMEnTER: Raffie, tell us, what happened next? Puppet: The hen pushed the bus or the airplane. Experimenter: Let's see if Raffie's right! Scene 3: (following animation of hen pushing the bus down the hill) Look, the hen pushed that one! Did Raffie guess right?

All children were tested individually in a quiet room away from their peers. Their responses were videorecorded for later analysis. Adult control participants were also tested one at a time, using exactly the same materials and procedure.

\footnotetext{
${ }^{8}$ Although the puppet's sentence was a guess, it was uttered in the past tense. As can be seen in Figure 1 . the use of the past tense was quite natural in the context of the rest of the story, which was also told in the past tense. We reasoned that young children are very often presented with stories and storybooks that describe events in the past tense, and thus would be more comfortable with such narratives.
} 


\subsubsection{Materials}

There were three conditions involving disjunctive test sentences such as The hen pushed the bus or the airplane. In the target '1-disjunct-true' (1DT) condition (e.g., Figure 1), the outcome of the story was such that only one of the disjuncts was verified, for example, the hen pushed only the bus. In the target '2-disjunct-true' (2DT) condition, the outcome of the story was such that both disjuncts were verified, for example, the hen would push both the bus and the airplane.

Participants also saw a '0-disjunct-true' (0DT) control condition, in which the hen would push neither object, as well as filler sentences that did not contain disjunction. All test and control sentences can be found in the Appendix.

Each participant saw four repetitions of both the 1DT condition and 2DT conditions, two repetitions of the 0DT control condition, and three disjunction-less fillers, for a total of thirteen experimental trials. These thirteen trials, presented in one of two pseudorandomized orders, were preceded by two training items: on one practice trial, the puppet made a guess that turned out to be clearly verified, and on the second, the puppet made a guess that turned out to be clearly wrong. The purpose of the practice trials was to show that the puppet was capable of making both good and bad guesses, and more generally to familiarize the participants with the task.

The purpose of the 1DT and 2DT conditions was to determine how participants interpreted disjunction. Collecting pairs of response types would allow us to determine whether participants were interpreting the disjunction inclusively, exclusively, or conjunctively. Table 1 contains the expected responses to the two target conditions, depending on the interpretation of disjunction. In short, participants' responses to the two target conditions would allow us to identify which of the three interpretations they were assigning to the disjunction.

\begin{tabular}{|c|c|c|}
\hline Interpretation of disjunction & 1DT & 2DT \\
\hline \hline Inclusive (literal) & yes & yes \\
\hline Exclusive & yes & no \\
\hline Conjunctive & no & yes \\
\hline
\end{tabular}

Table 1: Expected responses to the two target conditions, according to each interpretation of the disjunction.

\subsection{Results}

The data and $\mathrm{R}$ script for our experiment are available online at http://semanticsarchive. net/Archive/mE4YmYwN/TYCRSC-AcqDisj.html.

\subsubsection{Control conditions}

Children and adults performed as expected on control trials, with both groups displaying above $90 \%$ accuracy. 


\subsubsection{Target conditions}

The results from the target conditions are presented in Figure 2, We fitted a mixed-effects logit model on the children and adults responses to the 1DT condition, with Age group, Disjunction type, Language and the interaction between Disjunction type and Language as fixed effects (using the lme4 package in R, ?). Since all these factors are between-subject, the random effects only consisted of by-subject random intercepts. A comparison with a model without the effect of Age group revealed that this factor explained a substantive share of the variance $\left(\chi^{2}(1)=60, p<.001\right)$. Indeed, adults across both language groups and both forms of disjunction accepted on nearly all trials; in contrast, the child groups accepted much less often in this condition. As we will see in our discussion of the individual results, this tendency to reject more than adults in the 1DT condition may be indicative of a conjunctive interpretation of the disjunction.

A model with the same structure of fixed and random effects was fitted to responses from the 2DT condition, and showed that adults tended to reject across both language groups and both forms of disjunction; this result is consistent with previous findings suggesting adults interpret the disjunction exclusively. Children, on the other hand, were more accepting than adults in the 2DT condition (model comparison: $\chi^{2}(1)=84, p<.001$ ); children's yes-responses here could be consistent with inclusive or conjunctive interpretations of the disjunction $\sqrt[9]{9}$

A model with Age (standardized from the age in days), Condition, Language, Disjunction type and all possible interactions between these factors was fitted on the children's responses to the 1DT and 2DT conditions (with by-subject random intercepts and slopes for Condition, which was the only within-subject factor). The main effect of age did not seem significant (estimated $z=.3, p=.75$ ), nor did any of the seven interactions involving age. The model was not significantly better than a similar model without any effect of Age $\left(\chi^{2}(8)=3.9, p=\right.$ $.87)$.

\footnotetext{
${ }^{9}$ Our attempts to improve upon the methodology in Singh et al. (2015) appear to have led to observable differences in the adult results. In particular, Singh et al.'s adults did not differ in their responses to the $1 \mathrm{DT}$ and 2DT conditions (mean acceptances of $3.73 / 5$ vs. $3.35 / 5$, respectively), while our adults displayed a much clearer acceptance pattern in the 1DT condition, and a much clearer rejection pattern in the 2DT condition. Our results more clearly reveal the expected exclusivity inferences.
} 


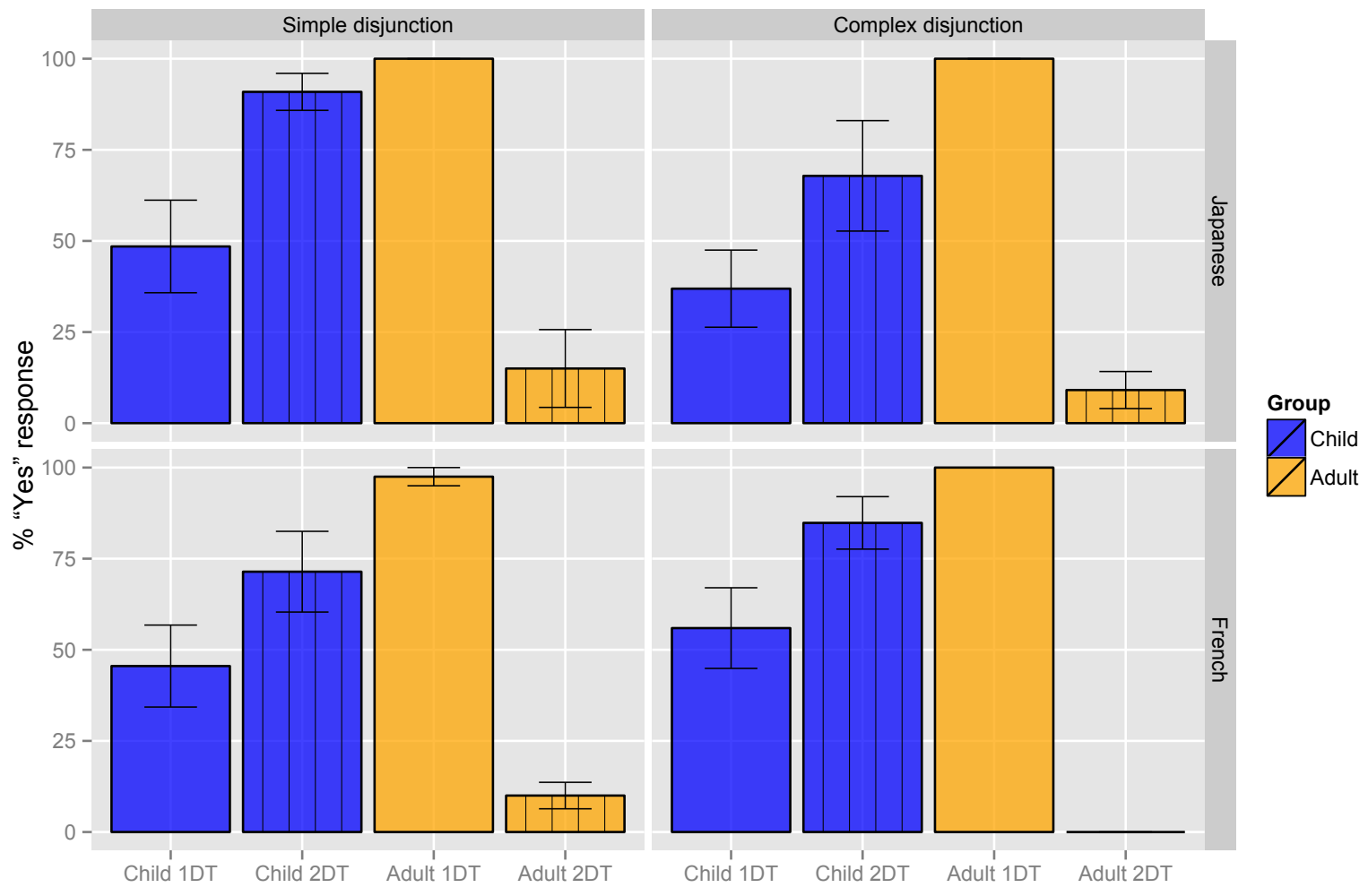

Figure 2: Percentage of yes-responses from children and adults to 1DT conditions (plain bars) and 2DT conditions (hashed bars), across disjunction types and languages.

In Figure 3, we represent each individual as a function of his/her responses on the 1DT and 2DT conditions. These responses were then used to categorize each participants for analyses, following the scheme presented in Table 1. Table 2 provides details regarding the number of children who fell into each category. 


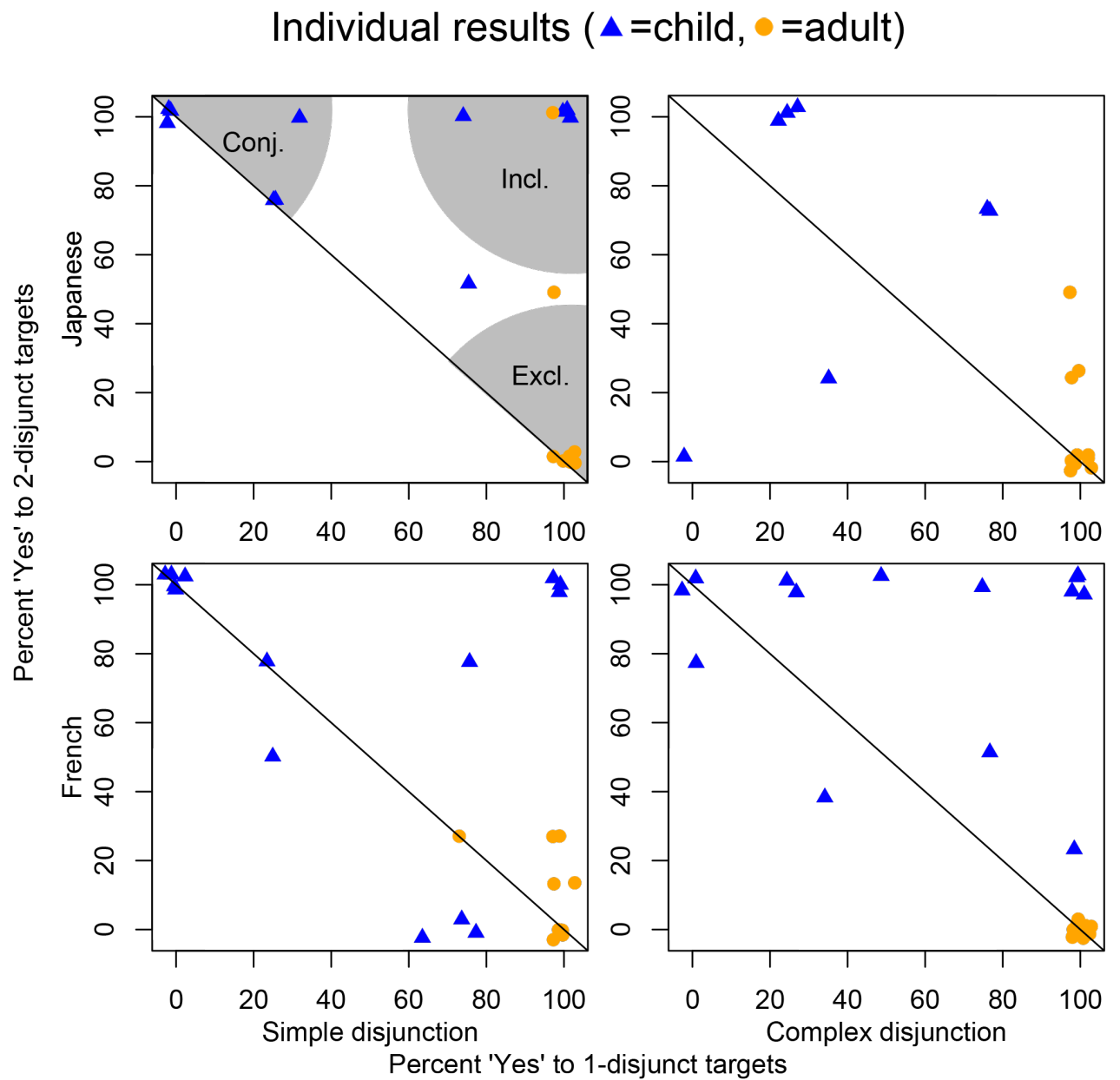

Figure 3: This figure represents each individual as a combination of his/her acceptance rate on 1DT targets (x-axis) and 2DT targets (y-axis). As indicated in the figure, (i) the bottom right corner in this space corresponds to participants who consistently accessed an exclusive reading (i.e. giving 'yes'-responses on at least three of four 1DT targets, and 'no'responses on at least three of four 2DT targets); (ii) the top right corner corresponds to inclusive responders (who gave at least three out of four 'yes' responses in both 1DT and 2DT conditions); and (iii) the top left corner corresponds to conjunctive responders (who rejected at least three of four 1DT targets but accepted at least three of four 2DT targets). See Table 2 for exact numbers of children in each category.

As we can see in Figure 3, adult participants in both language groups interpreted both forms of the disjunction exclusively. More precisely, 38 of 41 adults were categorized as exclusive, whereas only 3 of 46 children were exclusive $\left(\chi^{2}\right.$-test: $\left.\chi^{2}(1)=61, p<.001\right)$. The children instead could be categorized as inclusive or conjunctive; there was no significant difference observed between the number of inclusive and conjunctive children (14 vs. 19, out of $46 ; \chi^{2}$-test: $\chi^{2}(1)=0.8, p=.38$ ).

A quasi-Poisson model with Category as a unique fixed effect (inclusive, conjunctive or 


\begin{tabular}{|c|c|c|c|c|c|}
\hline & \multicolumn{2}{|c|}{ French } & $\begin{array}{l}\text { Jar } \\
\text { Simple }\end{array}$ & Japanese & Total \\
\hline Inclusive & 4 & 5 & 3 & 2 & 14 \\
\hline Conjunctive & 6 & 5 & 5 & 3 & 19 \\
\hline Exclusive & 3 & 0 & 0 & 0 & 3 \\
\hline Total (with NA) & 14 & 14 & 11 & 7 & 46 \\
\hline
\end{tabular}

Table 2: Counts of individual children categorized by language and disjunction type. The Total row includes 10 children who could not be categorized because they were at exactly $50 \%$ in at least one condition.

exclusive) was fitted to the data presented in Table 2 (thus fitting one $\lambda$-parameter for each row in the table). The log total number of children for each column was taken as the offset for the model ${ }^{10}$ This model was significantly better than a model with only an intercept (one $\lambda$ for the whole table, $\chi^{2}(2)=13, p=.001$ ) and a saturated Poisson model (with as many $\lambda$-parameters as cells in the table) was not significantly better, suggesting that the model with three parameters is sufficient to explain most of the variance $\left(\chi^{2}(9)=7.5, p=.59\right)$.

\subsubsection{Follow-up justifications}

Children were asked to repeat the puppet's sentences, to ensure that they had correctly heard them, and in particular, to ensure that they could reproduce the target disjunctive form. Then, after they gave their yes- or no-response, we elicited follow-up justifications. These justifications are useful because they confirm that children were indeed responding in a manner consistent with one of the relevant interpretations (inclusive, exclusive, or conjunctive). For example, inclusive responders would typically say 'yes' to both 1DT and 2DT conditions, and when asked why, would restate the relevant action in the story that made the disjunction true for them $(23),(24)$, Exclusive responders would crucially reject $2 \mathrm{DT}$ trials by referring to the fact that the character had carried out the action with both objects (25). In contrast, conjunctive responders would accept 2DT trials (26), but reject 1DT trials by making reference to the fact that the character had only carried out the action with one of the two objects $(27)$.

\section{Inclusive responders: Justifications for accepting 1DT}

a. Test sentence: Le mouton a acheté une guitare ou un piano.

'The sheep bought a guitar or a piano'

Justification: [oui] c'est parce que le mouton elle voulait acheter le piano, elle a dit qu'elle allait porter la guitare ou le piano

'[yes] because the sheep wanted to buy the piano, she(=Rafie) said that she (=the sheep) was going to carry the guitar or the piano' (DISJ-C13-O-A, 4;01,26)

\footnotetext{
${ }^{10}$ Although the data from children who could not be categorized were not fitted by the model, they were still counted for the offset. The offset in a Poisson model represents the exposure, and any child who passed the controls could in principle have belonged to any of the categories.
} 
b. Test sentence: Le mouton a acheté soit une guitare soit un piano.

'The sheep bought SOIT a guitar soIT a piano.'

Justification: [oui] elle a pris juste un piano

'[yes] she took just a piano.'

(DISJ-C30-S-B, 5;05,22)

c. Test sentence: Le singe a colorié soit le triangle soit le cercle.

'The monkey colored soIT the triangle soIT the circle.'

Justification: [oui] elle a colorié le rond

'[yes] she colored the circle'

(DISJ-C30-S-B, 5;05,22)

d. Test sentence: La poule a poussé soit le bus soit l'avion.

'The hen pushed soIT the bus soIT the airplane.'

Justification: [oui] elle a poussé l'autobus

'[yes] she pushed the bus'

(DISJ-C30-S-B, 5;05,22)

Inclusive responders: Justifications for accepting 2DT

a. Test sentence: La souris a porté une pomme ou une orange.

'The mouse carried an apple or an orange'

Justification: [oui] elle a dit que elle va porter la pomme ou l'orange, elle a fait bien

'[yes] She said she was going to carry the apple or the orange, she did good' (DISJ-C-13-O-A, 4;01,26)

b. Test sentence: La souris a porté soit une pomme soit une orange.

'The mouse carried soIT an apple sOIT an orange.'

Justification: [oui] c'est juste qu'elle a porté les deux et elle a dit les deux en fait

'[yes] it's just that she carried both and she(=Rafie) said both actually' (DISJC30-S-B, 5;05,22)

c. Test sentence: La poule a poussé soit le train soit le bateau.

'The hen pushed soIT the train soIT the boat.'

Justification: [oui] soit le bateau soit le train, c'est ce qu'elle a fait

'[yes] SOIT the boat soIT the train, that's what she did'

(DISJ-C30-S-B, $5 ; 05,22)$

\section{Exclusive responders: Justifications for rejecting 2DT}

a. Test sentence: Le lapin a peint la voiture ou le camion.

'The rabbit painted the car or the truck'

Justification: [non] pas content parce qu'elle a dit la voiture ou le camion [...] il a peint les deux

'[no] not happy because she said the car or the truck [...] he painted both' (DISJ-C01-O-A, 5;05,17)

b. Test sentence: La poule a poussé le train ou le bateau.

'The hen pushed the train or the boat.'

Justification: [non] parce qu'elle a poussé les deux

'[no] because she pushed both'

(DISJ-C01-O-A, 5;05,17)

c. Test sentence: La souris a porté soit une pomme soit une orange.

'The mouse carried sorT an apple soIT an orange' 
Justification: [non] elle a pris les deux

'[no] she took both'

(DISJ-C02-S-B, 5;03,19)

d. Test sentence: La poule a poussé le train ou le bateau.

'The hen pushed the train or the boat'

Justification: [non] parce qu'elle a poussé le bateau et le train

'[no] because she pushed the boat and the train'

(DISJ-C03-O-B, 5;02,17)

Conjunctive responders: Justifications for accepting 2DT

a. Test sentence: Le lapin a peint soit la voiture soit le camion.

'The rabbit painted soIT the car SOIT the plane'

Justification: [oui] parce qu'il a peint les deux

'[yes] because he painted both'

(DISJ-C02-S-B, 5;03,19)

b. Test sentence: Le lapin a peint soit la voiture soit le camion.

'The rabbit painted soIT the car soIT the plane'

Justification: [oui] parce qu'elle en a peint deux

'[yes] because she painted two of them'

(DISJ-C06-O-B, 4;06,02)

\section{Conjunctive responders: Justifications for rejecting 1DT}

a. Test sentence: La poule a poussé soit le bus soit l'avion.

'The hen pushed soit the bus soit the plane'

Justification: [non] parce qu'elle a pas poussé les deux [...] [elle avait dit] soit l'avion soit le bus

'[no] because she didn't push both [...] [she had said] soIT the plane sort the bus'

(DISJ-C02-S-B, 5;03,19)

b. Test sentence: Le mouton a acheté soit une guitare soit un piano.

'The sheep bought soIT a guitar SOIT a piano'

Justification: [non] parce que c'était un seul piano, c'était qu'un piano

'[no] because it was only a piano, it was just a piano' (DISJ-C06-O-B, 4;06,02)

c. Test sentence: La poule a poussé le bus ou l'avion.

'The hen pushed the bus or the plane'

Justification: [non] parce qu'elle a poussé que le camion

'[no] because she only pushed the truck'

(DISJ-C06-O-B, 4;06,02)

\section{Discussion}

To summarize, our experiment gave rise to three main findings. First, children compute fewer exclusivity inferences from disjunction than adults. Second, children do not appear to distinguish simple and complex forms of disjunction in comprehension. Finally, children in both language groups appear to access a non-adult-like conjunctive interpretation of both forms of disjunction. These three findings raise further questions about the acquisition of disjunction, and also connect to current theorizing about children's ability to compute scalar implicatures. 


\subsection{Children interpret disjunction inclusively}

Our first finding was that roughly half of the children in both language groups interpreted the disjunction inclusively. This was in contrast to adults, who all tended to interpret the disjunction exclusively. This result is consistent with much of the previous work on scalar implicatures, and on exclusivity inferences in particular (e.g., Chierchia et al. 2001; Gualmini et al. 2001, among others). On the alternatives-based approach to children's implicatures, described in Section 2.2.1, this result arises because children fail to access conjunction as an alternative to disjunction, and thereby are left with the literal inclusive interpretation of disjunction.

\subsection{On the role of obligatoriness}

Our second finding was that children did not appear to assign different interpretations to simple and complex disjunctions. Given that caregivers can be expected to use complex disjunctions only when the exclusive reading is verified, it may be surprising that we did not observe more exclusive interpretations from children in the complex disjunction conditions. That is, we do not seem to observe any facilitatory effect of the obligatoriness of the exclusivity inference for the complex disjunction.

It may be worth pointing out another example in the domain of inferences where obligatoriness seems not to have a facilitatory effect on children's performance, namely the case of plurality inferences, such as (28).

$$
\begin{aligned}
& \text { a. Emily fed pigs. } \\
& \text { b. } \text { Emily fed more than one pig. }
\end{aligned}
$$

Spector (2007) analyzes the 'more-than-one' meaning of plural morphology as a kind of scalar implicature which, like the exclusive implicature associated with complex disjunction, is very difficult, if not impossible, to cancel (see also Sauerland, Andersen \& Yatsushiro 2005; Zweig 2009; Ivlieva 2013; and Magri 2014 for relevant discussion and analyses). Given the obligatoriness of the plurality inference then, one might expect that children should show better performance on plurality inferences than classical scalar implicatures, which are optional and much more easily cancelled. Yet it has been shown that preschool-aged children compute fewer plurality inferences than adults, with performance completely on a par with their behaviour on standard cases of scalar implicature (Tieu, Bill, Romoli \& Crain 2014, 2015a for further evidence of weak meanings for the plural, see Sauerland, Andersen \& Yatsushiro (2005) (Section 5), who examined children's interpretation of bare plurals in questions, and Barner, Chow \& Yang (2009), who included a condition in which children treated some-NPs as compatible with contexts in which there was only a single object). Such data are surprising, because they suggest that hearing a sentence type exclusively in contexts where the strengthened interpretation holds is not sufficient for children to simply generalize to the strengthened meaning, 11

\footnotetext{
${ }^{11}$ Put slightly differently, if a child hears a sentence type only when the strengthened meaning is true, one could imagine the child simply deciding that the sentence type only has the strengthened meaning. It would then be surprising to see the child interpreting the sentence on its literal meaning, let alone only being able to access the literal meaning.
} 
A further connection to this issue and the role of the input comes from Morris s $(2008)$ corpus study examining transcripts of exchanges between children and their caregivers (these data are also described in $\mathrm{Su} 2014)$. Morris examined 240 transcriptions of audio-taped exchanges between 40 English-speaking children aged 2;00-5;00 (from the CHILDES database, MacWhinney 2000), and found that between 75\%-95\% of uses of or in both children's and their caregivers' productions were uttered in contexts where only one disjunct was verified. If this preference to use disjunction in contexts where only one disjunct is true holds for both simple and complex forms of disjunction, perhaps the input does not disproportionately drive children towards exclusive readings of complex disjunction any earlier than it does for simple disjunction. Alternatively, perhaps the unequivocal presence of complex disjunctions in such contexts is insufficient to lead to earlier exclusive readings of the complex disjunction. Some other factor, which may also prevent children from accessing the exclusive interpretation of the simple disjunction, prevents them from accessing this interpretation of the complex disjunction.

\subsection{Children interpret disjunction conjunctively}

Now let us address the conjunctive interpretation that was observed in roughly half of the children in both language groups. Recall that our method addressed the methodological concerns we raised about Singh et al.'s (2015) materials and method. We presented full stories supporting the test sentences, and also presented the test sentences as predictions (i.e. as the puppet's guesses), thereby avoiding potential infelicity arising from the use of disjunction. Yet we found, perhaps surprisingly, that the children we tested still accessed a conjunctive interpretation of disjunction. Furthermore, this pattern of behaviour is observed in two unrelated languages beyond English. This finding speaks against any explanation that appeals to confusion stemming from superficial similarity between the morphemes for disjunction and conjunction. It would be rather surprising to find that children across languages confuse these morphemes. It would be even more surprising to find that children confuse the morphemes even when the language in question contains two morphologically distinct forms for disjunction.

It is therefore unlikely that children are incorrectly assigning a conjunctive lexical semantics to the disjunction ${ }^{12}$ Instead, we argue that our data provide further support for Singh et al.'s (2015) proposal concerning how children arrive at the conjunctive interpretation. Given we observe the conjunctive pattern of behaviour across different languages, a parsimonious explanation is that children are arriving at this conjunctive meaning by the same means. In particular, we already have evidence from previous studies on implicatures that children are quite capable of computing inferences off of the alternatives that they can access. If, as Singh et al. (2015) propose, children can only access the individual disjuncts as alternatives for the disjunction, and not the conjunction, it is not very surprising that they arrive at a different inference from adults. Moreover, it is not so surprising that children do this across languages. The nature of the alternatives does not change from language to language: in the English, French, and Japanese experiments, children were given the individual

\footnotetext{
${ }^{12}$ Recall also that children consistently interpret disjunction inclusively in downward-entailing environments (Crain et al. 2002, Gualmini \& Crain 2002, Goro \& Akiba 2004, Jing et al. 2005, among many others).
} 
disjuncts - but not the conjunctive alternative - from which some of them then went on to compute the conjunctive meaning.

Singh et al.'s (2015) proposal can also be extended to account for the fact that we found no effect of disjunction type. Again, the nature of the alternatives remains unchanged across the two forms of disjunction. In order to compute the exclusive interpretation, children need to access conjunction as an alternative to disjunction, and to compute the conjunctive meaning, they need access to the individual disjuncts. It is not surprising that we observe the same behavioural profiles across simple and complex disjunctions: in neither case is the conjunctive alternative explicitly provided to the children, and in both cases the children are given the individual disjunct alternatives that they need to compute the conjunctive inference.

One may wonder why only half of the children computed a conjunctive meaning, while the other half retained the inclusive meaning. The account endorsed here is compatible with the observed split, but does not provide an explanation for why any given child would choose one interpretation over the other. Imagine that the child passes through an early stage of development where she cannot access the relevant lexical alternative, i.e. conjunction. Such a child can only fall back on two possible interpretations, namely the inclusive and conjunctive ones. A priori, it is not clear what should force them to choose one reading over the other. In principle, the choice would come down to whether or not to exhaustify. Even in adults, however, we do not necessarily have a precise understanding of all the factors that drive the computation of inferences in some cases and not others. To reiterate, alternativesbased approaches merely predict that children (who may otherwise appear to be inclusive or conjunctive responders) will be capable of computing exclusivity inferences once they have the relevant conjunctive alternative; it does not explain when or why they actually go on to do so, nor which reading they will default to otherwise.

\section{Conclusion}

The findings of our experiment reveal differences between children and adults in the interpretation of disjunction. Adults interpreted simple and complex forms of disjunction exclusively. In contrast, 4- and 5-year-old children computed fewer exclusive readings, instead preferring inclusive and conjunctive readings; this was the case for both simple and complex forms of disjunction, in both languages. Importantly, we tried to ensure that the materials and task made the use of both forms of disjunction felicitous; we can therefore be confident that the conjunctive interpretations we observed were not the result of any infelicity involving the materials or sentences.

Our findings can be explained within existing proposals about children's abilities to compute scalar implicatures: children can compute implicatures only when the required alternatives are accessible (Barner et al. 2011; Singh et al. 2015; Tieu et al. 2015b). On this alternatives-based approach, the key to children's success or failure lies in the nature of the alternatives. In the case of disjunction, children lack the conjunctive alternative, and thus do not compute exclusivity implicatures. But they can easily access the individual disjunct alternatives, which are contained within the sentences, and can therefore compute a non-adult-like conjunctive inference from the disjunction. On such an approach then, both 
aspects of the disparity between children and adults are explained.

\section{Appendix: Test sentences}

\section{DT condition}

(29) French - complex (SOIT...SOIT)

a. Le lapin a peint soit la voiture soit le camion.

'Bunny painted soIT the car SOIT the truck.'

b. Le singe a ouvert soit la fenêtre soit la porte.

'Monkey opened SOIT the window SOIT the door.'

c. La poule a poussé soit le train soit le bateau.

'Hen pushed soIT the train soIT the boat.'

d. La souris a porté soit une pomme soit une orange.

'Mouse carried sOIT an apple soIT an orange.'

Japanese - complex (KA...KA)

a. Usagi-san-wa kuruma-ka torakku-ka-ni iro-o nutta

Bunny-Ms.-TOP car-KA truck-KA-to color-ACC painted

'Ms. Rabbit painted the car or the truck.'

b. Osaru-san-wa mado-ka doa-ka-o aketa. monkey-Mr.-TOP window-KA door-KA-ACC opened

'Mr. Monkey opened the windor or the door.'

c. Niwatori-san-wa densya-ka booto-ka-o osita.

Chicken-Ms.-TOP train-KA boat-KA-ACC pushed

'Ms. Chicken pushed the train or the boat.'

d. Nezumi-san-wa ringo-ka orenzi-ka-o hakonda.

Mouse-Ms.-TOP apple-KA orange-KA-ACC carried

'Ms. Mouse carried the apple or the orange.'

(31) French - simple (OU)

a. Le lapin a peint la voiture ou le camion.

'Bunny painted the car or the truck.'

b. Le singe a ouvert la fenêtre ou la porte.

'Monkey opened the window or the door.'

c. La poule a poussé le train ou le bateau.

'Hen pushed the train or the boat.'

d. La souris a porté une pomme ou une orange.

'Mouse carried an apple or an orange.'

(32) Japanese - simple (KA)

a. Usagi-san-wa kuruma-ka torakku-ni iro-o nutta

Bunny-Ms.-TOP car-KA truck-to color-ACC painted

'Ms. Rabbit painted the car or the truck.' 
b. Osaru-san-wa mado-ka doa-o aketa. monkey-Mr.-TOP window-KA door-ACC opened 'Mr. Monkey opened the windor or the door.'

c. Niwatori-san-wa densya-ka booto-o osita. Chicken-Ms.-TOP train-KA boat-ACC pushed 'Ms. Chicken pushed the train or the boat.'

d. Nezumi-san-wa ringo-ka orenzi-o hakonda. Mouse-Ms.-TOP apple-KA orange-ACC carried 'Ms. Mouse carried the apple or the orange.'

\section{DT condition}

French - complex (SOIT...sOIT)

a. La poule a poussé soit le bus soit l'avion. 'Hen pushed soIT the bus SOIT the plane.'

b. La souris a porté soit une banane soit une carotte. 'Mouse carried SOIT a banana soIT a carrot.'

c. Le singe a colorié soit le triangle soit le cercle. 'Monkey coloured SOIT the triangle SOIT the circle.'

d. Le mouton a acheté soit une guitare soit un piano. 'Sheep bought SOIT a guitar SOIT a piano.'

(34) Japanese - complex (KA...KA)

a. Niwatori-san-wa Bus-ka hikooki-ka-o osita. chicken-Ms.-TOP bus-KA plane-KA-ACC pushed 'Ms. Chicken pushed the bus or the plane.'

b. Nezumi-san-wa banana-ka ninzin-ka-o hakonda mouse-Ms.-TOP banana-KA carrot-KA-ACC carried 'Ms. Mouse carried the banana or the carrot.'

c. Osaru-san-wa sankaku-ka maru-ka-no iro-o nutta. Monkey-Mr.-TOP triangle-KA circle-KA-GEN color-ACC painted 'Mr. Monkey painted the triangle or the circle.'

d. Hizuzi-san-wa gitaa-ka piano-ka-o katta. Sheep-Ms.-TOP guitar-KA piano-KA-ACC bought

'Ms. Sheep bought the guitar or the piano.'

(35) French - simple (OU)

a. La poule a poussé le bus ou l'avion. 'Hen pushed the bus or the plane.'

b. La souris a porté une banane ou une carotte. 'Mouse carried a banana or a carrot.'

c. Le singe a colorié le triangle ou le cercle. 'Monkey coloured the triangle or the circle.'

d. Le mouton a acheté une guitare ou un piano. 'Sheep bought a guitar or a piano.' 
Japanese - simple (KA)

a. Niwatori-san-wa Bus-ka hikooki-o osita. chicken-Ms.-TOP bus-KA plane-ACC pushed 'Ms. Chicken pushed the bus or the plane.'

b. Nezumi-san-wa banana-ka ninzin-o hakonda mouse-Ms.-TOP banana-KA carrot-ACC carried 'Ms. Mouse carried the banana or the carrot.'

c. Osaru-san-wa sankaku-ka maru-no iro-o nutta. Monkey-Mr.-TOP triangle-KA circle-GEN color-ACC painted 'Mr. Monkey painted the triangle or the circle.'

d. Hizuzi-san-wa gitaa-ka piano-o katta. Sheep-Ms.-TOP guitar-KA piano-ACC bought 'Ms. Sheep bought the guitar or the piano.'

\section{ODT condition}

(37) French - complex (SOIT...sOIT)

a. Le singe a colorié soit un coeur soit un losange.

'Monkey coloured SOIT a heart soIT a diamond.'

b. Le pingouin a peint soit les fruits soit les fleurs.

'Penguin painted SOIT the fruit SOIT the flowers.'

Japanese - complex (KA...KA)

a. Osaru-san-wa haato-ka daiya-ka-no iro-o nutta.

Monkey-Mr.-TOP heart-KA diamond-KA-GEN color-ACC painted

'Mr. Monkey painted the heart or the diamond.'

b. Pengin-san-wa fruutu-ka ohana-ka-o kaita.

Pinguin-Mr.-TOP fruits-KA flower-KA-ACC painted

'Mr. Penguin painted the fruits or the flower.'

(39) French - simple (OU)

a. Le singe a colorié un coeur ou un losange.

'Monkey coloured a heart or a diamond.'

b. Le pingouin a peint les fruits ou les fleurs.

'Penguin painted the fruit or the flowers.'

Japanese - simple (KA)

a. Osaru-san-wa haato-ka daiya-no iro-o nutta.

Monkey-Mr.-TOP heart-KA diamond-GEN color-ACC painted

'Mr. Monkey painted the heart or the diamond.'

b. Pengin-san-wa fruutu-ka ohana-o kaita.

Pinguin-Mr.-TOP fruits-KA flower-ACC painted

'Mr. Penguin painted the fruits or the flower.'

\section{Filler items}


a. Le lapin a cueilli une banane. 'Rabbit picked a banana.' (yes-target)

Le lapin a cueilli une poire. 'Rabbit picked a pear.' (no-target)

b. Le singe a pris son parapluie. 'Monkey took his umbrella.' (yes-target)

Le singe a pris ses bottes. 'Monkey took his boots.' (no-target)

c. Le cochon a mis son chapeau. 'Pig wore his hat.' (yes-target)

Le cochon a mis son écharpe. 'Pig wore his scarf.' (no-target)

(42) Japanese

a. Usagi-san-wa banana-o totta.

Rabbit-Ms.-TOP banana-ACC took

'Ms. Rabbit took the banana.' (yes-target)

Usagi-san-wa nasi-o totta.

Rabbit-Ms.-TOP pear-ACC took

'Ms. Rabbit took the pear.' (no-target)

b. Osaru-san-wa kasa-o totta.

Monkey-Mr.TOP umbrella-ACC took

'Mr. Monkey took the umbrella.' (yes-target)

Osaru-san-wa Nagagutu-o totta.

Monkey-Mr.TOP rainboots-ACC took

'Mr. Monkey took the boots.' (no-target)

c. Buta-san-wa boosi-o kabutta.

pig-Mr.-TOP hat-ACC put.on

'Mr. Pig put on the hat.' (yes-target)

Buta-san-wa mafuraa-o sita.

Pig-Mr.-TOP scarf-ACC did

'Mr. Pig put on the scarf.' (no-target)

\section{References}

Alonso Ovalle, Luis. 2005. Disjunction in Alternative Semantics: University of Massachusetts at Amherst dissertation.

Barner, David, Neon Brooks \& Alan Bale. 2011. Accessing the unsaid: the role of scalar alternatives in children's pragmatic inferences. Cognition 188. 87-96.

Barner, David, Katherine Chow \& Shu-Ju Yang. 2009. Finding one's meaning: A test of the relation between quantifiers and integers in language development. Cognitive Psychology 58. 195-219.

Braine, Martin D. S. \& Barbara Rumain. 1981. Children's comprehension of 'or': Evidence for a sequence of competencies. Journal of Experimental Child Psychology 31. 46-70.

Chemla, Emmanuel. 2009. Similarity: Towards a unified account of scalar implicatures, free choice permission, and presupposition projection. Ms., LSCP. 
Chierchia, Gennaro. 2013. Logic in Grammar: Polarity, Free Choice, and Intervention. Oxford University Press.

Chierchia, Gennaro, Stephen Crain, Maria Teresa Guasti \& Rosalind Thornton. 2001. 'Some' and 'or': A study on the emergence of logical form. In S. Catherine Howell, Sarah A. Fish \& Thea Keith-Lucas (eds.), Boston University Conference on Language Development (BUCLD) 24, 22-44. Somerville, Massachusetts: Cascadilla Press.

Chierchia, Gennaro, Maria Teresa Guasti, Andrea Gualmini, Luisa Meroni, Stephen Crain \& Francesca Foppolo. 2004. Semantic and pragmatic competence in children and adults comprehension of or. In Ira Noveck \& Dan Sperber (eds.), Experimental Pragmatics, 283-300. Palgrave Macmillan.

Crain, Stephen, Amanda Gardner, Andrea Gualmini \& Beth Rabbin. 2002. Children's command of negation. In Yukio Otsu (ed.), Proceedings of the 3rd Tokyo Conference on Psycholinguistics, 71-95. Tokyo: Hituzi Publishing Company.

Crain, Stephen \& Rosalind Thornton. 1998. Investigations in Universal Grammar: A Guide to Experiments on the Acquisition of Syntax and Semantics. Cambridge, Massachusetts: MIT Press.

Crain, Stephen \& Rosalind Thornton. 2000. Investigations in Universal Grammar: A Guide to Experiments on the Acquisition of Syntax and Semantics. Cambridge, Massachusetts: MIT Press.

Fox, Danny. 2007. Free choice and the theory of scalar implicatures. In Uli Sauerland \& Penka Stateva (eds.), Presupposition and Implicature in Compositional Semantics, 71-120. Basingstoke: Palgrave Macmillan.

Franke, Michael. 2011. Quantity implicatures, exhaustive interpretation, and rational conversation. Semantics and Pragmatics 4(1). 1-82. doi:10.3765/sp.4.1.

Goro, Takuya \& Sachie Akiba. 2004. The acquisition of disjunction and positive polarity in Japanese. In G. Garding \& M. Tsujimura (eds.), Proceedings of WCCFL 23, 101-114. Somerville, MA: Cascadilla Press.

Goro, Takuya, Utako Minai \& Stephen Crain. 2005. Bringing out the logic in child language. In Leah Bateman \& Cherlon Ussery (eds.), Proceedings of the 35th Annual Meeting of the North East Linguistic Society, 245-256. Amherst, MA: GLSA Publications.

Grice, Paul. 1975. Logic and conversation. In Donald Davidson \& Gilbert H. Harman (eds.), The Logic of Grammar, 64-75. Encino, CA: Dickenson Publishing Company.

Gualmini, Andrea \& Stephen Crain. 2002. Why no child or adult must learn DeMorgan's laws. In S. Catherine Howell, Sarah A. Fish \& Thea Keith-Lucas (eds.), Proceedings of the 24th Annual Boston University Conference on Language Development, 367-378. Somerville, MA: Cascadilla Press.

Gualmini, Andrea, Stephen Crain, Luisa Meroni, Gennaro Chierchia \& Maria Teresa Guasti. 2001. At the semantics/pragmatics interface in child language. In Rachel Hastings, Brendan Jackson \& Zsofia Zvolenszky (eds.), Semantics and Linguistic Theory (SALT) 11, 231-247. Cornell University, Ithaca, NY: CLC Publications.

Gualmini, Andrea, Luisa Meroni \& Stephen Crain. 2003. An asymmetric universal in child language. In Matthias Weisgerber (ed.), Proceedings of Sinn und Bedeutung VI, 136-148. Konstanz, Germany: Fachbereich Sprachwissenschaft der Universitat Konstanz.

Hochstein, Lara, Alan Bale, Danny Fox \& David Barner. 2014. Ignorance and inference: Do problems with Gricean epistemic reasoning explain children's difficulty with scalar 
implicature? Journal of Semantics doi:10.1093/jos/ffu015.

Huang, Yi Ting, Elizabeth Spelke \& Jesse Snedeker. 2013. What exactly do numbers mean? Language Learning and Development 9. 105-129.

Ivlieva, Natalia. 2013. Scalar implicatures and the grammar of plurality and disjunction: Massachusetts Institute of Technology dissertation.

Jing, Chunyuan, Stephen Crain \& Ching-Fen Hsu. 2005. The interpretation of focus in Chinese: Child versus adult language. In Yukio Otsu (ed.), Proceedings of the 6th Tokyo Conference on Psycholinguistics, 165-190. Tokyo: Hituzi Publishing Company.

Klinedinst, Nathan. 2007. Plurality and Possibility: UCLA dissertation.

Kratzer, Angelika \& Junko Shimoyama. 2002. Indeterminate pronouns: The view from Japanese. In Yukio Otsu (ed.), Proceedings of the Tokyo conference on psycholinguistics, vol. 3, 1-25. Tokyo: Hituzi Syobo.

MacWhinney, Brian. 2000. The CHILDES project: Tools for analyzing talk. Lawrence Erlbaum Associates 3rd edn.

Magri, Giorgio. 2014. An account for the homogeneity effects triggered by plural definites and conjunction based on double strengthening. In Salvatore Pistoia Reda (ed.), Pragmatics, Semantics and the Case of Scalar Implicatures, 99-145. Palgrave Macmillan.

Meyer, Marie-Christine. 2015. Generalized free choice and missing alternatives. Journal of Semantics .

Morris, Bradley J. 2008. Logically speaking: Evidence for item-based acquisition of the connectives AND \& OR. Journal of Cognition and Development 9. 67-88.

Notley, Anna, Peng Zhou, Britta Jensen \& Stephen Crain. 2012. Children's interpretation of disjunction in the scope of 'before': A comparison of English and Mandarin. Journal of Child Language 39(3). 482-522.

Noveck, Ira. 2001. When children are more logical than adults: experimental investigations of scalar implicatures. Cognition 78(8). 165-188.

Papafragou, Anna \& Julien Musolino. 2003. Scalar implicatures: experiments at the semantics-pragmatics interface. Cognition 86. 253-282.

Paris, Scott G. 1973. Comprehension of language connectives and propositional logical relationships. Joural of Experimental Child Psychology 16. 278-291.

van Rooij, Robert. 2010. Conjunctive interpretation of disjunction. Semantics and Pragmatics 3(11). 1-28. doi:10.3765/sp.3.11.

Sauerland, Uli, Jan Andersen \& Kazuko Yatsushiro. 2005. The plural is semantically unmarked. In Stephan Kepser \& Marga Reis (eds.), Linguistic Evidence: Empirical, Theoretical, and Computational Perspectives, 413-434. Mouton de Gruyter.

Singh, Raj, Ken Wexler, Andrea Astle, Deepthi Kamawar \& Danny Fox. 2015. Children interpret disjunction as conjunction: consequences for the theory of scalar implicatures. Accepted pending revisions.

Spector, Benjamin. 2007. Aspects of the pragmatics of plural morphology: On higher-order implicatures. In Uli Sauerland \& Penka Stateva (eds.), Presupposition and Implicature in Compositional Semantics, 243-281. Palgrave.

Spector, Benjamin. 2014. Global positive polarity items and obligatory exhaustivity. Semantics $\&$ Pragmatics 7(11). 1-61.

Spector, Benjamin. to appear. Comparing exhaustivity operators (minimal worlds vs. innocent exclusion). Semantics \& Pragmatics . 
Su, Yi (Esther). 2013. Scalar implicatures and downward entailment in child Mandarin. Journal of East Asian Linguistics 22(2). 167-187.

$\mathrm{Su}, \mathrm{Yi}$ (Esther). 2014. The acquisition of logical connectives in child Mandarin. Language Acquisition 21(2). 119-155.

Su, Yi (Esther), Peng Zhou \& Stephen Crain. 2012. Downward entailment in child Mandarin. Journal of Child Language 39. 957-990.

Tieu, Lyn, Cory Bill, Jacopo Romoli \& Stephen Crain. 2014. Plurality inferences are scalar implicatures: Evidence from acquisition. In Todd Snider (ed.), Proceedings of the 24th Semantics and Linguistic Theory Conference, 122-136.

Tieu, Lyn, Cory Bill, Jacopo Romoli \& Stephen Crain. 2015a. Plurality inferences are scalar implicatures: Further evidence from acquisition. Paper presented at the Workshop on Experimental and Crosslinguistic Evidence for the Distinction between Implicatures and Presuppositions.

Tieu, Lyn, Jacopo Romoli, Peng Zhou \& Stephen Crain. 2015b. Children's knowledge of free choice inferences and scalar implicatures. Journal of Semantics 33(2). 269-298.

van Rooij, Robert \& Katrin Schulz. 2004. Pragmatic meaning and non-monotonic reasoning: The case of exhaustive interpretation. Linguistics and Philosophy .

Zhou, Peng, Jacopo Romoli \& Stephen Crain. 2013. Chidren's knowledge of alternatives. In Todd Snider (ed.), Semantics and Linguistic Theory (SALT) 23, 632-651. Cornell University Ithaca, NY: CLC Publications.

Zweig, Eytan. 2009. Number neutral bare plurals and the multiplicity agreement. Linguistics and Philosophy 32. 353-407. 